\title{
Alimentação em tempos de pandemia do Coronavírus: a ressignificação de uma prática cotidiana e dietética
}

\author{
Feeding in times of pandemic Coronavirus: the resignification of an everyday and dietary practice \\ Alimentación en tiempos de pandemia coronavirus: la resignificación de una práctica cotidiana y \\ dietética
}

Recebido: 01/03/2021 | Revisado: 11/03/2021 | Aceito: 15/03/2021 | Publicado: 23/03/2021

\author{
Aline Gomes Santana \\ ORCID: https://orcid.org/0000-0002-8432-5149 \\ Universidade Federal Rural de Pernambuco, Brasil \\ E-mail: alinegsan157@gmail.com \\ Maria Lucia Gurgel da Costa \\ ORCID: https://orcid.org/0000-0001-8614-685X \\ Universidade Federal de Pernambuco, Brasil \\ E-mail: malugurgelfono@gmail.com \\ Neide Kazue Sakugawa Shinohara \\ ORCID: https://orcid.org/0000-0001-8356-874X \\ Universidade Federal Rural de Pernambuco, Brasil \\ E-mail: neide.shinohara@ufrpe.br
}

\begin{abstract}
Resumo
O texto tem como objetivo discutir o comportamento dos brasileiros no que tange a prática de comer em tempos de pandemia do coronavírus. O estudo busca analisar como a alimentação foi ressignificada em decorrência do isolamento social sugerido pela Organização Mundial de Saúde (OMS) e pela Organização Pan-Americana de Saúde (OPAS) e adotado por alguns estados da federação. A partir da observação netnográfica verificamos como o serviço delivery, através dos meios digitais, tornou-se um elo de comunicação entre consumidores e empresários, para manter ativas atividades comerciais, exigindo nessa crise maior atenção às práticas higiênicas na preparação e entrega dos produtos. Para as empresas de serviços de alimentação que não tinham forte histórico de delivery, essa modalidade de entrega contribuiu para a sobrevida dos empreendimentos. De modo geral, pudemos avaliar como práticas de alimentação ancoradas nas ferramentas digitais em tempos de afastamento social, assumiram um simbolismo cultural, econômico e tecnológico, para o enfrentamento do surto pandêmico de coronavírus.
\end{abstract}

Palavras-chave: Alimentação; Ressignificação; Delivery; COVID-19.

\begin{abstract}
The text aims to discuss the behavior of Brazilians regarding the practice of eating in times of coronavirus pandemic. The study seeks to analyze how food was resignified due to the social isolation suggested by the World Health Organization (WHO) and the Pan American Health Organization (PAHO) and adopted by some states of the federation. From the netnographic observation we verified how the delivery service, through digital media, has become a communication link between consumers and entrepreneurs, to maintain active commercial activities, requiring in this crisis greater attention to hygienic practices in the preparation and delivery of products. For food service companies that did not have a strong track record, this mode of delivery contributed to the survival of the enterprises. In general, we were able to evaluate how feeding practices anchored in digital tools in times of social remoteness, assumed a cultural, economic and technological symbolism, in order to cope with the pandemic outbreak of coronavirus.
\end{abstract}

Keywords: Food; Redefinition; Delivery; COVID-19.

\section{Resumen}

El texto tiene como objetivo discutir el comportamiento de los brasileños con respecto a la práctica de comer en tiempos de pandemia de coronavirus. El estudio busca analizar cómo los alimentos fueron resignados debido al aislamiento social sugerido por la Organización Mundial de la Salud (OMS) y la Organización Panamericana de la Salud (OPS) y adoptados por algunos estados de la federación. A partir de la observación netnoográfica verificamos cómo el servicio de prestación, a través de medios digitales, se ha convertido en un enlace de comunicación entre consumidores y emprendedores, para mantener actividades comerciales activas, requiriendo en esta crisis una mayor atención a las prácticas higiénicas en la preparación y entrega de productos. Para las empresas de servicios alimentarios que no tenían una sólida trayectoria, este modo de entrega contribuyó a la supervivencia de las empresas. En general, pudimos evaluar 
cómo las prácticas de alimentación ancladas en herramientas digitales en tiempos de lejanía social, asumieron un simbolismo cultural, económico y tecnológico, con el fin de hacer frente al brote pandémico de coronavirus.

Palabras clave: Alimentación; Resignificación; Entrega; COVID-19.

\section{Introdução}

O comportamento alimentar do homem distingue-se dos outros animais não apenas por saber preparar refeições no ambiente da cozinha, que está intimamente ligada, em diferentes graus, à geografia, dietética, cultura, religião, mas também pela comensalidade e pela função social que envolve as refeições individuais e coletivos (Flandrin \& Montanari, 1998). Mais do que o simples ato fisiológico de ingerir um alimento, comer tem se tornado um momento de interação social, levando a comportamentos de convívio regionalizados ou temporais (Montanari, 2009).

Comer é um ato carregado de significados culturais, patrimônio imaterial, que traduz povos, nações, construção de civilizações formando grupos étnicos, laços familiares e de amizade. Comer não é apenas um ato biológico usando uma intricada rede de reações químicas, é antes de tudo, um ato simbólico e tradutor de sinais, reconhecimento de formas e texturas, pois é um ato que une memória, desejo, necessidade biológica, rituais e é entendido como um ato patrimonial humano (Lima, Neto \& Farias, 2015).

No início do século 19, depois da queda da nobreza na França, os chefs e cozinheiros saíram dos palácios e se tornaram empreendedores, abrindo restaurantes para atender nobres e burgueses, oferecendo suas criações gastronômicas ao público. Com o tempo surgiu a classe de operários, que passaram a fazer parte da clientela, com preparações mais populares e preço acessível (Freixa \& Chaves, 2009). A popularização dos restaurantes criou conceitos de alimentação e tipos de serviços, produzindo aspectos próprios e código gastronômico para cada restaurante. Esses novos ares, definiram experiências sensoriais, gostos locais, territórios e expectativas de consumo e fidelidade.

Flutuações na compra de alimentos prontos para consumo em restaurantes, geralmente enfrentam oscilações decorrentes de crises econômicas, intempéries climáticas e desafios sanitários, como o cenário de pandemia pelo coronavírus, em que o Brasil foi atingido a partir de março de 2020. A recomendação sanitária no Brasil para conter o avanço do vírus, foi a adoção do distanciamento e isolamento social, sugerido pela Organização Mundial da Saúde (OSM) e a Organização Pan-Americana de Saúde (OPAS). Em Pernambuco, foi permitido que somente os serviços essenciais como hospitais, supermercados, depósitos de água e gás, farmácias, lojas de produtos de higiene e limpeza e bancos pudessem continuar funcionando.

No caso dos restaurantes, somente entregas delivery estavam autorizadas, para evitar aglomerações, necessitando que os empresários desse setor de alimentos pudessem se adaptar a esse novo desafio pandêmico, uma vez que no Brasil, não existe a cultura massiva de entrega domiciliar de alimentos prontos para consumo. Uma ferramenta que auxiliou na compra de alimentos in natura, processados e acabados, foi a internet através do uso das redes sociais e do serviço de e-commerce, que ajudaram a alavancar as vendas no varejo, mostrando alternativas para manter a memória gustativa de diversas etnias na segurança do lar.

$\mathrm{Na}$ nova realidade brasileira amedrontada pelo coronavírus, atividades que para muitos eram realizadas de forma automática, à revelia de qualquer ordem e tempo, passaram a ter um novo significado, assumindo uma nova perspectiva cultural, sanitária e de consumo. E entre tais ações, o ato de comer pode ser percebido como uma manifestação carregada de simbolismos, variáveis a cada grupo e/ou sujeito que o realize, com liberdade de tomada de decisão em situações adversas, como nessa crise pandêmica onde fez-se necessário aos brasileiros ficar em casa e reconverter suas práticas de consumo. Partindo desta perspectiva o texto busca analisar como a alimentação foi ressignificada diante das novas determinações sociais oriundas da pandemia do coronavírus. 


\section{Metodologia}

Este estudo trata-se de uma pesquisa observacional, por isto empregou revisão bibliográfica descritivo-exploratória para ratificar as ideias apresentadas, trazendo autores como Borges (2010), Casotti (2002), Freixa (2009), Flandrin (1998) e Montanari $(1998,2009)$. Foi também utilizada a netnografia, sendo esta ferramenta fundamental para elaboração do estudo, diante da incapacidade de realização de observação direta, tendo em vista o isolamento social imposto durante a pesquisa. De acordo com Kozinetes (2010) a netnografia possibilita a investigação e interpretação comportamental dos indivíduos e grupos sociais no campo virtual e/ou real através da observação pelo uso das mídias digitais. Deste modo, esta ferramenta de pesquisa funcionou como principal aliada para a análise proposta pelo texto.

Ao longo da pesquisa foram observadas as ações desenvolvidas pela OMS e OPAS e as manifestações dos sujeitos e comércio varejista ligados diretamente a temática estudada, sendo tratados temas como pandemia; coronavírus; isolamento social e a ressignificação da sociedade durante a crise pandêmica. Para embasamento do estudo, a busca de informações compreendeu o período de dezembro de 2020 a fevereiro de 2021. Tal período foi delimitado visando estabelecer um recorte de espaço e tempo que permitisse trazer informações mais atualizadas aos leitores, tendo em vista que até o término da pesquisa o isolamento social continuava em vigor, pelo crescente número de casos de COVID-19 no Brasil e no mundo.

\section{O Brasil e o Mundo em Tempos de Coronavírus (COVID-19)}

Segundo o Ministério da Saúde (2020) "Coronavírus é uma família de vírus que podem causar infecções respiratórias graves". O novo agente do coronavírus foi descoberto em dezembro de 2019, após casos registrados na China.

“A Organização Pan-Americana de Saúde declarou em 30 de janeiro de 2020, que o surto da doença causada pelo novo coronavírus (COVID-19) constitui uma Emergência de Saúde Pública de Importância Internacional - o mais alto nível de alerta da Organização, conforme previsto no Regulamento Sanitário Internacional. Em 11 de março de 2020, a COVID-19 foi caracterizada pela OMS como uma pandemia. (OPAS, 2020).”

Iniciado na China, o surto causado pelo coronavírus se expandiu e tomou proporções mundiais, rompendo fronteiras geográficas e sociais, infectando e matando pessoas em todo o mundo. Esse surto localizado inicialmente na Ásia, que atravessou fronteiras e povos sem se intimidar frente a diferentes grupos e classes sociais, vem causando danos e deixando cicatrizes profundas na humanidade. De repente, o mundo se viu refém de um agente biológico invisível e devastador para a raça humana, chamado popularmente de Coronavírus.

Conforme divulgado pela OPAS (2020), mais de 100 países localizados em todos os continentes possuem casos da COVID-19. A tabela abaixo apresenta o número de casos notificados pela OPAS, até o dia 27 de fevereiro de 2020:

Tabela 1. Número de casos da COVID-19 pelo mundo.

\begin{tabular}{c|c|c}
\hline Região & Casos & Óbitos \\
\hline Africana & 2.703 .899 & 2.703 .899 \\
\hline Américas & 47.814 .602 & 1.120 .144 \\
\hline Europeia & 36.294 .484 & 805.071 \\
\hline Mediterrâneo Oriental & 5.951 .021 & 138.834 \\
\hline Pacífico Ocidental & 1.516 .916 & 26.804 \\
\hline Sudeste Asiático & 13.141 .859 & 201.828 \\
\hline
\end{tabular}

Fonte: Site OPAS Brasil.

De acordo com o Ministério da Saúde, 
“A COVID-19 é uma doença causada pelo coronavírus, denominado SARS-CoV-2, que apresenta um espectro clínico variando de infecções assintomáticas a quadros graves. De acordo com a Organização Mundial de Saúde, a maioria (cerca de 80\%) dos pacientes com COVID-19 podem ser assintomáticos ou oligossintomáticos (poucos sintomas), e aproximadamente $20 \%$ dos casos detectados requer atendimento hospitalar por apresentarem dificuldade respiratória, dos quais aproximadamente 5\% podem necessitar de suporte ventilatório. (Ministério da Saúde, 2020).”

Apesar dos estudos crescentes e incansáveis de pesquisadores em diferentes universidades e centros de pesquisa espalhados pelo mundo, ainda há muitas incertezas sobre o coronavírus, o que tem dificultado a tomada de decisões quanto ao combate ao vírus e suas consequências. No Brasil, o número de infectados cresce a cada dia, gerando e/ou agravando uma série de problemas sociais, entre eles a falta de leitos em hospitais; adoecimento dos profissionais de saúde, crise econômica com o aumento do desemprego, decorrente do afastamento de grande parte do segundo setor da economia, os comerciários, e o crescente número de mortes, muito além da previsão epidemiológica para o mesmo período.

No Brasil, o vírus já causou vítimas com sintomas incapacitantes ou quadros letais em todos os 26 Estados da Federação e no Distrito Federal, sendo o aumento dos casos intenso, bastante rápido e expressivo. Na tabela abaixo são apresentados o quantitativo detalhado de casos no Brasil até o dia 27 de fevereiro, segundo informações disponibilizadas nos relatórios do Ministério da Saúde e OPAS:

Tabela 2. Dados de vítimas do COVID-19 no Brasil.

\begin{tabular}{c|c|c}
\hline & $\begin{array}{c}\text { Casos } \\
\text { Confirmados }\end{array}$ & Óbitos \\
\hline Dados no Brasil & 10.517 .232 & 254.221 \\
\hline Dados Global & 107.423 .526 & 2.360 .280 \\
\hline
\end{tabular}

Fonte: Sites MS e OPAS.

Essa quantidade de pessoas que podemos observar na Tabela 2 representa um grande e importante quantitativo de recurso humano da sociedade, muitos adultos jovens em plena atividade laboral, que foram acometidos pela doença e, em alguns casos, perderam suas vidas. Associada a mobilização por um plano de vacinação mundial (executado de acordo com o governo de cada nação), a OMS e os governos dos países acometidos pelos casos ainda crescentes de infectados, seguem emitindo medidas sanitárias e sugerindo a contenção de aglomerações, para não sobrecarregar o sistema público de saúde e evitar a proliferação da COVID-19, na tentativa de reduzir o aumento de vítimas debilitadas e casos de óbitos. Entre as medidas estabelecidas pela OMS, a prioridade é manter o isolamento social, como medida simples e eficaz, pois diminui a circulação e aglomeração de pessoas nas ruas e ambientes sociais. Essa medida restritiva acaba promovendo a desaceleração de crescimento exponencial do vírus e consequentemente a diminuição dos infectados.

Ficar em casa e evitar ao máximo a exposição social, tornou-se então a nova ordem sanitária mundial, para combater um inimigo aparentemente simples que não pode ser visto a olho nu, mas pode levar à morte rápida pessoas de todas as idades e classes, sem quaisquer distinções. Essa austeridade mundial tem sido demandada no Brasil, reformulando o modo como a população se comporta e desempenha suas práticas sociais e de consumo, entre elas o ato de comer de forma segura em contexto de mudanças no mercado food service durante o isolamento social.

\section{A Prática da Comensalidade}

Desde que o homem assumiu o domínio do ato de cozer, sua relação com a comida passou de um ato biológico para uma prática social identitária, que lhe permite a construção e manutenção das relações interpessoais.

Comer estabelece uma relação direta com diferentes questões de sociabilidade. A comensalidade, ou o partilhar de 
alimentos, pode ser percebido como um ritual básico do vínculo humano, teoria tratada por Flandrin e Montanari ao dizer que:

"Acredita-se, geralmente, que comportamento alimentar do homem distingue-se do dos animais não apenas pela cozinha - ligada, em maior ou menor grau, a uma dietética e a prescrições religiosas -, mas também pela comensalidade e pela função social das refeições. [...] Com o risco de cair num antropomorfismo descabido, pode-se perceber, nas refeições das próprias feras, um prazer em comer junto, uma certa cumplicidade atenta a uma clara hierarquia, que comporta precedências, e uma espécie de etiqueta adaptada a sua sociedade [...]. (Flandrin \& Montanari, 1998, pp. 32-35).”

Essa interação oriunda da comensalidade tem papel vital para a formação de elos nas diferentes relações que o sujeito constrói, seja ela profissional, de amizade e principalmente familiar. Tal percepção orientou Maffesoli (2002) a descrever a mesa como um local de comunicação e ritualização social.

Observando as práticas alimentares dos indivíduos e/ou grupos podemos identificar algumas de suas características comportamentais, formulando uma relação entre seus hábitos alimentares e sua rotina. Deste modo, as refeições acabam refletindo a realidade vivida pelos sujeitos considerando o tempo e o contexto social no qual estão inseridos.

O alimento é a matéria nutritiva e a comida não é apenas uma substância alimentar, mas é também um modo, um estilo e a forma de alimentar-se é a transformação do alimento através da culinária. Neste sentido, comer proporciona uma relação de intimidade do ser humano e seus pares, pois há o envolvimento do convívio social no processo de escolha dos alimentos e das transformações destes, através de práticas tecnológicas na culinária (Garcia, 2003).

A relação evoluiu com o tempo, principalmente com a entrada da mulher no mercado de trabalho e o ingresso do homem na cozinha. Inicialmente, como pontua Casotti (2002), foram percebidas mudanças no comer a partir da Segunda Guerra Mundial, com a chegada de novidades tecnológicas como o micro-ondas, freezer, comidas pré-prontas ou prontas, abreviando bastante o tempo do feminino na cozinha.

A indústria de alimentos cresceu à medida que as mulheres saíram de seus lares e foram impulsionadas ao mercado de trabalho, levando a alimentação doméstica como alimento-serviço de conveniência. A indústria passou a cozinhar no lugar do consumidor e posteriormente passou também a ditar a dieta rápida a baixo custo, otimizando a facilidade de consumo e padronizando esse hábito alimentar à moda contemporânea (Fonseca, Souza, Frozi \& Pereira, 2011).

Alimentar-se fora do lar passou a ser uma prática comum, sendo um fenômeno observado no Brasil no final de 1980, época em que ocorre a expansão dos restaurantes por quilo, por pessoas da classe média e alta, com alto índice de escolaridade, influenciado por estilo de vida globalizado, manifestação de reordenação de atribuições tradicionais relativas à divisão de gênero no trabalho e dentro do lar (Montebello \& Colaço, 2008).

A concentração de pessoas nos centros urbanos fez surgir as metrópoles e, junto a isso, um grande contingente de indivíduos que, em sua maioria, moravam distantes do trabalho, o que os obrigava a realizar as refeições em restaurantes populares ou lanchonetes, de forma rápida e geralmente mais barata que a refeição convencional, chamada de fast food american way of life (modo de vida no estilo americano) - que invade rapidamente o mundo após a Segunda Guerra Mundial, sendo uma mudança intensa e progressiva que foi ditando um novo estilo de alimentação (Freixa \& Chaves, 2009). Nesse estilo de vida urbano, a comensalidade se caracteriza pela escassez de tempo para o preparo e consumo de alimentos, levando a algumas doenças crônicas pelo teor hipercalórica e a reduzida quantidade de nutrientes da comida, motivo de preocupação pelo aumento do perfil de morbimortalidade, necessitando de intervenção e mudanças nos padrões alimentares (Garcia, 2003).

A partir das mudanças citadas anteriormente, percebemos que a relação entre a divisão do tempo e as atividades sociais pode ser encarada como fator determinante dos hábitos alimentares do cotidiano, visto que as refeições têm a função não somente de demarcar a divisão do tempo, mas também de representar as dinâmicas sociais quando considerados os rituais existentes à mesa, como afirma Borges (2010). Partindo deste princípio de que o contexto social influencia nas práticas da comensalidade, podemos perceber que a pandemia do coronavírus vivenciada pelo mundo também tem reverberado na alimentação de muitas 
pessoas no Brasil.

A determinação de ficar em casa, obrigou muitos brasileiros a reformular o ato de comer. Algumas pessoas tiveram de retomar a prática de cozinhar no lar, que fora deixada de lado diante das demandas de tempo do cotidiano agitado em que viviam antes do isolamento social. Outros sujeitos recorreram ao serviço delivery, por não estarem familiarizados com a cozinha ou pela simples busca de praticidade. Independente da forma como os brasileiros passaram a exercitar a comensalidade, de fato as relações interpessoais e a alimentação sofreram mudanças com a nova realidade social e sanitária em que o país se encontra.

\section{Comer em Família}

Com a evolução da sociedade após a entrada da mulher no mercado de trabalho, e o surgimento de eletrodomésticos que facilitam e abreviam as tarefas domésticas, a mesa deixou de ser o ponto centralizador da família, que se viu inserida em uma nova realidade onde os sujeitos foram gradativamente direcionados a realizar refeições sozinhos e de forma rápida, tendo o auxílio dos fast-foods, comidas prontas, e serviços delivery para acentuar a praticidade e redução do tempo.

Essa reformulação da comensalidade, condicionou muitos indivíduos a abandonar a cozinha e/ou o ato de comer em família. E a mesa deixou de ser um agente aproximador da família, como descreveu Maffesoli (2002). A ritualização das refeições em família carrega um simbolismo familiar que perpassa gerações ao longo da história da existência humana, iniciando com o nome da pré-história chegando aos dias de hoje.

Com o avanço social, a mesa fora sendo deixada de lado e a comensalidade, como ato de partilhar alimentos, sofre uma ressignificação social, sendo uma ferramenta de construção de relações sociais e comerciais. O processo de digressão da mesa pela família, não ocorreu de forma imediata, mas paulatinamente de acordo com o modo como os membros deste conglomerado passaram a enxergar o mundo e a importância da manutenção familiar. Entretanto, como afirma Borges (2010) as refeições são um espelho da rotina de determinada época, que auxiliam na identificação do contexto em que os sujeitos estão inseridos.

A pandemia do coronavírus tem contribuído para uma nova reformulação nas práticas alimentares dos sujeitos. $\mathrm{O}$ contexto de isolamento social tem levado muitas famílias de volta a mesa, fazendo desta um lugar de comunicação e retomada de vínculos humanos, outrora esquecidos. Além da retomada da família como grupo de comensalidade, a realidade pandêmica trouxe à tona outras formas de interação alimentar, que se encontram ancoradas no uso das tecnologias digitais para fazer acontecer o processo de interação social.

Diante da impossibilidade de encontros presenciais, as pessoas têm recorrido ao uso de mídias digitais para compartilhar diferentes momentos de sua rotina, estando a refeição entre as tais ações vivenciadas à distância de modo virtual; com trocas de informações, experiências gastronômicas e receitas das mais variadas preparações. Essa prática de sucesso foi compartilhada por muitas pessoas, em sua maioria jovens, que moram só e realizavam suas refeições na "rua", pela praticidade e ganho de tempo. Muitos relataram que viram nessa quarentena a necessidade de evitar sair de casa e que, comprando alimentos in natura com entrega domiciliar, começaram a cozinhar, sentindo uma satisfação pessoal e o resgate da memória gustativa.

Essa adequação do sujeito diante da crise do coronavírus, fortalece as ideias discutidas por Bauman (2017), ao descrever o homem como um ser adaptável que tem cada vez mais, principalmente com o uso das novas tecnologias, se adaptado e vivenciado novas realidades diante da modernidade que vive com o mundo em constante transformação.

A impossibilidade de sair de casa e vivenciar o cotidiano frenético, onde cada ação é cronometrada e a refeição carrega o valor de obrigatoriedade nos intervalos entre cada tarefa, faz com que as pessoas revejam suas interações sociais e familiares, e estas veem na comensalidade uma oportunidade de interagir e manter viva a relação com o mundo e com outros sujeitos, sejam estes membros da família ou amigos.

A desconstrução do cotidiano causada pela crise pandêmica, impõe nas refeições valores sociais e sentimentais, pois através do ato de comer o indivíduo consegue interagir e perceber-se como integrante de um ou mais grupos sociais, mesmo que 
as vezes o faça de forma remota através dos meios digitais.

\section{O Delivery de Cada Dia}

Com a orientação de isolamento social e o decreto de empresas para que seus funcionários desempenhem o home office, o mercado em geral sofreu uma enorme queda de produtividade presencial e a economia vem passando por uma profunda crise econômica. Muitos estabelecimentos da economia secundária tiveram de fechar suas portas e suspender suas atividades ou se reprogramar. Mas, para fugir da crise, alguns empreendedores têm recorrido ao serviço de entrega (delivery) para as residências ou ambientes de trabalho, a fim de manter suas atividades e diminuir o prejuízo diante dessa crise local e mundial.

O aumento de infectados e mortos pela COVID-19 contribui para a segregação da população, elevando o distanciamento voluntário. A decisão de ficar em casa faz com que as pessoas criem dependência da entrega domiciliar dos mais diferentes segmentos comerciais, sendo o delivery de alimentos prontos ou in natura um segmento em destaque, que contribui para mitigar os índices econômicos negativos. Conforme Beloni (2020), a entrega delivery com o passar do período de confinamento, apresentou aumento no volume de pedidos e variedade de tipos de preparações, tornando-se um aliado para muitas pessoas que tem buscado obedecer ao isolamento social, evitando ir a supermercados e restaurantes.

Além de evitar a saída de casa e consequente exposição ao vírus, a diversidade de restaurantes e pratos são atrativos no serviço de entrega. $\mathrm{O}$ ato aparentemente simples de pedir comida acaba sendo replicado e incentivado a partir da influência de alguém próximo e/ou das mídias digitais. A propagação do consumo delivery desencadeou o estímulo a novas formas de negócio, principalmente do pequeno empresário da comunidade local, tais como mercadinho, padaria, farmácia, lanchonete, cafés, restaurante, costureira (máscaras) e outros profissionais; que viram no serviço de entrega uma oportunidade de crescimento e manutenção comercial.

Percebendo a demanda pelo delivery muitas empresas ajustaram sua forma de comercialização, sendo preciso observar algumas práticas higiênicas para executar as entregas, visto os riscos de contaminação pelo coronavírus. Entre as medidas estão o distanciamento de 1,5 metro, o uso de máscara e uso de álcool $70^{\circ}$ INPM pelos entregadores, estímulo do pagamento via cartão para evitar a circulação de dinheiro e diminuição de contato entre entregadores e clientes. Algumas empresas passaram a oferecer a opção de 'entrega sem contato', neste modo as empresas e os entregadores são orientados pelos clientes no ato da compra a deixar a encomenda na porta ou local definido pelo cliente, evitando contato direto.

Com todos os protocolos de segurança empresas como Rappi, Uber eats, Ifood e James têm aumentado o número de entregas. Como exemplo, temos a empresa Rappi que afirma ter tido um crescimento de $30 \%$ em sua demanda, de acordo com o exposto por Beloni (2020).

$\mathrm{O}$ aumento no serviço delivery de alimentos reforça ainda mais a reconversão vivenciada nas práticas alimentares dos brasileiros. A forma como consomem seus alimentos foi recondicionada pela pandemia e mais uma vez, assim como na comensalidade em família perto ou a distância, o uso das tecnologias torna-se essencial para a execução das refeições, pois para ter acesso aos serviços de entrega faz-se necessário aos clientes o uso de aplicativos e outros meios digitais, que lhes permitam contatar a empresa a qual pretendem adquirir o alimento desejado, o horário de conveniência e a forma de pagamento, estabelecendo relações comerciais de confiança.

Além da forma como pedem o alimento, o manejo do mesmo também serve para representar a realidade em que o consumidor se encontra. Pois, o cuidado com a limpeza na entrega manifestado através de protocolos de higienização como uso de álcool gel, luva e máscara carregam o simbolismo do receio e cuidado social dos indivíduos diante do risco de contaminação pelo coronavírus. Esta conduta reforça a ideia de Fonseca, Souza, Frozi \& Pereira (2011) a respeito do processo de compra de alimentos, quando os autores dizem que um alimento comprado e consumido deixa de ser apenas um alimento e passa a ser uma união de significados, constituindo-se em informação, transmitindo uma situação e ganhando nova dimensão ao ser fisicamente 
consumido.

\section{Surgimento de Chefs no Isolamento Social}

Outra manifestação alimentar percebida durante o período de isolamento social, foi o surgimento de novos 'chefs de cozinha'. A reclusão forçada tem levado muitas pessoas a se reinventarem à medida que procuram alternativas para fugir do tédio de se sentirem aprisionados em suas casas, exercitando e expondo ao mundo - através das mídias digitais - a arte da cozinha.

De acordo com Maffesoli (2002), a alimentação tem o papel de formar e fortalecer os elos familiares e sociais. Nessa perspectiva, comer deixa de ser somente um ato biológico e assume o papel de mediador social. Para muitos cozinhar tem assumido um novo significado, servindo como ferramenta para fuga do estresse causado pela privação social durante a pandemia. Pessoas tem se arriscado nas panelas, na cutelaria e no uso dos eletrodomésticos, e tem se surpreendido com resultados positivos em suas produções gastronômicas.

Apesar de não haver estudos e consequentemente quantificação do surgimento de novos cozinheiros durante a pandemia, podemos identificar a partir da observação virtual e de depoimentos, pessoas utilizando a internet para compartilhar suas aventuras na cozinha. As receitas vão desde preparações com proteínas, massas, doces, entre outros pratos, até a harmonização de bebidas alcóolicas e não alcóolicas; sempre pontuando como é prazeroso voltar às origens e reaprender os valores culturais de cozinhar para 'si' ou para a família, vendo nesse momento gastronômico a possibilidade de passar tempo em família, o que certamente fará parte das memórias gustativas dos envolvidos. Os meios digitais também têm servido para a manifestação de novas experiências, como a troca de receitas através de diferentes redes sociais, aproximando familiares, amigos e até mesmo desconhecidos.

Através dos discursos virtuais é possível perceber que as pessoas têm aderido à prática de cozinhar por diferentes motivos. Alguns passaram a cozinhar por não desejar utilizar os serviços delivery; outros o fizeram para melhorar suas relações sociais, buscando se aproximar mais das pessoas com quem convivem, sejam elas familiares ou amigos; outros ainda recorreram a prática de cozinhar por cuidados com a saúde, ao possuírem ou até mesmo aproveitarem o isolamento para iniciar uma dieta alimentar mais saudável; e ainda há os que adentraram na cozinha em busca de diversão.

Seja qual for o motivo, a relação das pessoas com a comida não será mais a mesma diante da pandemia que o mundo está presenciando. A necessidade das pessoas de ficarem em casa tem gerado uma reformulação dos seus hábitos alimentares. A disponibilidade do tempo condiciona os indivíduos a desenvolver novas práticas de consumo alimentar, reforçando a ideia de Borges (2010) ao afirmar que a relação entre a divisão do tempo e as atividades sociais podem ser encaradas como fatores determinantes dos hábitos alimentares cotidianos.

\section{Comensalidade: uma Partilha Solidária}

A pandemia trouxe uma nova realidade para o Brasil, que além de enfrentar uma doença desconhecida que tem acometido milhares de pessoas de diferentes idades e classes sociais, levando um número crescente de mortes; também tem causado e/ou exposto outras crises no país. Com o isolamento social, muitas empresas e estabelecimentos comerciais tiveram de encerrar suas atividades, este tempo sem atividades acabou levando muitos empreendimentos a reduzir seus gastos ou até mesmo ao fechamento completo, gerando falência diante da falta de circulação de pessoas e impacto na economia. Com este novo cenário econômico o país tem enfrentado, além de uma crise na saúde, uma crise financeira que ainda não pode ser calculada tendo em vista o aumento dos casos de contaminados pelo vírus, o que gera a impossibilidade de findar o isolamento social e, consequentemente, retomar as atividades comerciais no país.

Muitas pessoas acabaram perdendo suas fontes de renda diante desta crise, e a desigualdade social tornou-se mais clara 
e visível. De acordo com Gerbelli (2020), em uma matéria publicada no site de notícias G1, o "pico da crise do coronavírus deve ter 2,5 milhões a mais de desempregados no país", reforçando o aumento da desigualdade, um fato que pode ser percebido no cotidiano brasileiro.

A Agência Brasil de Notícias também divulgou, em abril de 2020 - início da pandemia, um alerta da Oxfam, entidade que atua em 90 países, sobre o aumento da pobreza no Brasil. Segundo a publicação da Agência Brasil (2020), o coronavírus poderia levar 500 milhões de pessoas para a linha da pobreza. Além destas informações a mídia brasileira também tem divulgado a crise econômica gerada pela pandemia, e os problemas que esta tem trazido para milhares de brasileiros que não têm como manter-se, por falta de condições financeiras. No entanto, essa situação de dor e tristeza, tem gerado também uma onda de ações solidárias pelo país, que buscam através da partilha de bens e principalmente de alimentos oferecer um afago a quem mais sofre.

Segundo notícias publicadas em sites como a Folha de S. Paulo (2020), muitos cidadãos comuns e empresas têm criado e executado ações para auxiliar as pessoas em situação de vulnerabilidade social, através da doação de alimentos (cestas básicas) e produtos de limpeza e higiene pessoal, a fim de contribuir para a diminuição da penúria financeira destas pessoas, que foram atingidas pela crise durante a pandemia e se veem desamparadas pelo poder público.

Um exemplo dessas ações solidárias foram as doações feitas aos caminhoneiros. Como os motoristas não estavam conseguindo comprar alimentos nas estradas em virtude do fechamento obrigatório dos restaurantes, muitos encontravam a solidariedade ao longo do seu percurso, através da doação de marmitas, bebidas e produtos de higiene pessoal para que pudessem continuar a jornada de entrega das mercadorias e não houvesse desabastecimento, principalmente de alimentos, uma vez que não existe nenhuma região no território nacional que seja totalmente autossuficiente na produção de todos os grupos de alimentos.

Apesar do isolamento social, alguns indivíduos têm saído de casa para encontrar cura interior e contaminar outras pessoas com ações de solidariedade. E o alimento tem sido a ferramenta de aproximação e manifestação do desejo das pessoas em cuidar umas das outras na nova realidade, nunca vivenciada antes no Brasil e no mundo.

Muitas empresas dos mais diferentes ramos também têm direcionado parte de suas ações para oferecer ajuda a quem mais precisa. É possível identificar doações de alimentos de diversos modos, seja na entrega de cestas básicas para a produção de comida em casa por um determinado período ou na distribuição de pratos prontos para satisfação da necessidade imediata de comer. Muitos restaurantes também têm aberto suas portas, não para atender clientes, mas para distribuir comida a quem precisa, ressignificando sua atuação e principalmente seus valores, tendo a caridade como prioridade acima do lucro.

Sejam pessoas físicas ou empresas, a partilha de alimento como ação solidária tem ressignificado o sentido da comensalidade, impulsionando esta prática para um patamar superior que vai além do alcance do prazer gustativo, atingindo a satisfação emocional de quem doa e principalmente acalentando e auxiliando quem tem sofrido com a pandemia do coronavírus e precisa de socorro e proteção.

\section{Considerações Finais}

Mais do que consumir alimentos, comer tornou-se uma forma de manifestação social. Através dos hábitos culinários o sujeito consegue demonstrar sua identidade, além de construir e manter relações interpessoais.

A pandemia tem servido como impulso para a reconversão alimentar dos sujeitos, que tem buscado alternativas para enfrentar o isolamento e proteger-se do risco de contaminação pelo coronavírus.

O distanciamento social tem gerado nos indivíduos uma carência nunca vivida antes. Como resultado desse desejo de estar junto às pessoas, muitos sujeitos têm retomado costumes abandonados a tempos, como o ato de cozinhar e de comer em família. E essas novas condutas, ou melhor dizendo, esse avivamento de condutas outrora orientadoras do comportamento identitário e social dos sujeitos, visto sua relevância, tem contribuído para a ressignificação da comensalidade.

Para muitos, comer havia se tornado um ato biológico, realizado entre as muitas idas e vindas do frenesi cotidiano da 
modernidade, sendo algumas vezes até deixado de lado pela necessidade de cumprir as demandas sociais. Com a parada repentina e forçada do mundo, diante da pandemia do coronavírus, as pessoas se viram perdidas e carentes em virtude da falta de rotina e correria a qual estavam tão acostumados, e fez-se necessário encontrar novas formas de manter-se vivo e ativo na obrigação de ficar em casa.

Diante deste fenômeno pandêmico, o ato de comer foi reconvertido e novas ações passaram a nortear a prática de consumir alimentos. $\mathrm{O}$ ato da comensalidade em família voltou a fazer parte da realidade de muitos que se viram aprisionados com os seus parentes e passaram a valorizar a circunstância de partilhar o alimento.

$\mathrm{O}$ uso do serviço de entrega de comida também se tornou um aliado para quem deseja consumir pratos prontos, mas não quer arriscar-se a sair de casa para evitar a contaminação pelo coronavírus. A prática do delivery também tem auxiliado os estabelecimentos comercias que se viram obrigados a suspender suas atividades diante das ordens de isolamento social dadas pela OMS, e o serviço de entrega passou a ser relevante mantenedor das relações comerciais entre o empreendedor e os seus clientes, tendo o uso das tecnologias digitais como ferramenta para esta interação.

Dentro do contexto de isolamento social, também é possível identificar outra mudança de comportamento das pessoas com a alimentação, o surgimento de novos 'chefs' do isolamento. Algumas pessoas encontraram na prática de cozinhar uma forma de interagir com outros sujeitos que também estão reclusos em seus lares e tem as mídias digitais como parceiras e/ou fontes de informação e contato com o mundo.

Nessa nova realidade trazida pela pandemia do coronavírus para o Brasil, a comensalidade assume um novo significado diante do desejo de ajudar as pessoas que tem vivido o desespero de não ter alimento para praticar o ato de comer no seu significado mais simples - o de satisfazer as necessidades biológicas. Neste contexto, a partilha do alimento é reconvertida para ir além do prazer de comer, atendendo aos que necessitam de comida, mas não as tem pelas dificuldades financeiras e sociais em que se encontram.

Seja na comensalidade vivida em família, no consumo de alimentos por entrega domiciliar, no ato de cozinhar e trocar conhecimentos culinários ou na partilha solidária de alimentos; a forma como as pessoas enxergam a alimentação tem mudado. Um novo paradigma tem sido dado aos alimentos, as refeições e as novas tecnologias digitais têm contribuído para que as pessoas vivenciem experiências de consumo e compartilhamento de conteúdo gastronômico, e todas estas ações têm ressignificado a simples, mas necessária prática de comer.

Tendo em vista a situação de crise que o país ainda vivencia e as mudanças que o Brasil já enfrenta e que se espera enfrentar, decorrentes das exigências requeridas pela realidade com e pós pandemia, projetamos a necessidade de continuar observando e estudando as ressignificações a que sociedade precisará passar, para que possamos continuar vivendo em sociedade (mesmo que de forma mais distante) e consumindo alimentos nos mais diferentes modos. Sob esta perspectiva, identificamos a relevância de realizar novos estudos que deem continuidade a temática abordada neste escrito, permeando pontos como novas práticas de alimentação e a reconversão dos alimentos no contexto econômico e nutricional; a fim de apresentar novas pesquisas que tragam dados que contribuam para a informação e debate social.

\section{Referências}

Adjunto, G. (2020) Coronavírus pode levar 500 milhões de pessoas para a pobreza. Website Agencia Brasil.

Beloni, L. (2020) Coronavírus impulsiona delivery no Brasil e muda rotina de restaurantes e consumidores. Website Gaya. https://www.agenciagaya.com.br/2020/03/24/coronavirus-impulsiona-delivery-no-brasil-e-muda-rotina-de-restaurantes-e-consumidores/

Borges, A. M. B. (2010) Comensalidade: a mesa como espaço de comunicação e hospitalidade. XXXIII Congresso Brasileiro de Ciências da Comunicação.

Casotti, L. (2002). À mesa com a família: um estudo do comportamento do consumidor de alimentos. Mauad.

CPFL, Instituto. Café filosófico: Relato de um encontro com Zygmunt Bauman por Mário Mazilli. (2017). Website Instituto CPFL. https://institutocpfl.org.br/podcast/zygmunt-bauman-estrategias-para-a-vida/. 
Research, Society and Development, v. 10, n. 3, e50410313442, 2021

(CC BY 4.0) | ISSN 2525-3409 | DOI: http://dx.doi.org/10.33448/rsd-v10i3.13442

Flandrin, J. L. \& Montanari, M. (1998) História da Alimentação. Estação Liberdade.

Freixa, D. \& Chaves, G. (2009) Gastronomia no Brasil e no Mundo. Senac.

Fonseca, A. B., Souza, T. S. N. D., Frozi, D. S. \& Pereira, R. A. (2011). Modernidade alimentar e consumo de alimentos: contribuições sócio-antropológicas para a pesquisa em nutrição. Ciência \& Saúde Coletiva, 16(9), 3853-3862.

Garcia, R. W. D. (2003). Reflexos da globalização na cultura alimentar: considerações sobre as mudanças na alimentação urbana. Revista de Nutrição, 16(4), 483-492.

Gerbelli, L. G. (2020) Pico da crise do coronavírus deve ter 2,5 milhões a mais de desempregados no país, prevê Santander. Website G1. https://g1.globo.com/economia/noticia/2020/04/06/pico-da-crise-do-coronavirus-deve-ter-25-milhoes-a-mais-desempregados-no-pais-preve-santander.ghtml.

Kozinets, R. V. (2010). Netnografia: realizando pesquisa etnográfica online. Penso Editora LTDA.

Lima, R. S., Neto, J. A. F. \& Farias, R. C. P. (2015). Alimentação, comida e cultura: o exercício da comensalidade. Revista Demetra: Alimentação, Nutrição \& Saúde, 10(3), 507-522.

Maffesoli, M. (2002). Mesa espaço de comunicação. In: DIAS, Cecilia Maria de Moraes (Org.). Hospitalidade: reflexões e perspectivas. São Paulo: Editora Manole.

Montanari, M. (2009). O Mundo na Cozinha: História, identidade, trocas. Estação Liberdade.

Montebello, N. P. \& Collaço, J. H. L. (2008) Gastronomia: Cortes \& Recortes. Senac.

MS. Ministério da Saúde. (2020). Coronavírus - Covid-19. Website do Ministério da Saúde.

OPAS, Organização Pan-Americana de Saúde. (2020) OPAS/-Brasil. Folha informativa - COVID-19 Escritório da OPAS e da OMS no Brasil. Website OPAS.

São Paulo. (2016). Doações de cestas básicas digitais e alimentos combatem a fome na pandemia. Website Folha/UOL. https://www1.folha.uol.com.br/empreendedorsocial/2020/06/doacoes-de-cestas-basicas-digitais-e-alimentos-combatem-a-fome-na-pandemia.shtml. 